\title{
Accident prevention in SME using ORM
}

\author{
Jørgensen, Kirsten; Duijm, Nijs Jan; Troen, Hanne
}

\section{Published in:}

Safety Science

Link to article, DOI:

10.1016/j.ssci.2010.02.008

Publication date:

2010

\section{Document Version}

Publisher's PDF, also known as Version of record

Link back to DTU Orbit

\section{Citation (APA):}

Jørgensen, K., Duijm, N. J., \& Troen, H. (2010). Accident prevention in SME using ORM. Safety Science, 48(8), 1036-1043. https://doi.org/10.1016/j.ssci.2010.02.008

\section{General rights}

Copyright and moral rights for the publications made accessible in the public portal are retained by the authors and/or other copyright owners and it is a condition of accessing publications that users recognise and abide by the legal requirements associated with these rights.

- Users may download and print one copy of any publication from the public portal for the purpose of private study or research.

- You may not further distribute the material or use it for any profit-making activity or commercial gain

- You may freely distribute the URL identifying the publication in the public portal

If you believe that this document breaches copyright please contact us providing details, and we will remove access to the work immediately and investigate your claim. 


\title{
Accident prevention in SME using ORM
}

\author{
K. Jørgensen ${ }^{\mathrm{a}, *}$, N.J. Duijm ${ }^{\mathrm{a}}$, H. Troen ${ }^{\mathrm{b}}$ \\ ${ }^{a}$ Department of Management Engineering, Technical University of Denmark (DTU), Produktionstorvet, Building 424, DK-2800 Kgs. Lyngby, Denmark \\ ${ }^{\mathrm{b}}$ KemiRisk, Maglekærvej 50, 2680 Solrød Strand, Denmark
}

\section{A R T I C L E I N F O}

\section{Article history:}

Received 21 February 2009

Received in revised form 26 October 2009

Accepted 6 February 2010

Available online $\mathrm{xxxx}$

\section{Keywords:}

Occupational

Accident

Prevention

SMEs

Risk evaluation

\begin{abstract}
A B S T R A C T
The occupational risk model (ORM) developed by the Dutch workgroup occupational risk model WORM has been transferred to a Danish context, with the aim of creating a more simple system, particularly for SMEs. The ORM identifies the activities in a person's daily work that contribute most to the person's risk and also identifies which conditions need to be changed in order to reduce that risk. Our investigation seeks to determine whether we can use the ORM method to collect information about risks in SMEs and, if so, whether we can present this information in a way that allows SMEs to use it constructively. Finally, we seek to evaluate the impact of this method on occupational safety in SMEs, as the project also focuses on management factors that can motivate the SMEs to heighten their risk-awareness and expand their own initiatives. The present paper describes the methodological approaches applied and some of the preliminary findings obtained during field observations.
\end{abstract}

(c) 2010 Published by Elsevier Ltd.

\section{Introduction}

It is well known that the levels of work-related injuries, fatalities and illness in small enterprises are unacceptably high and at the same time it is recognized that health and safety management in the small enterprises faces considerable challenges arising from organization and culture of work (European Agency for Safety and Health at Work, 2003; Hasle et al., 2004a,b; Walters, 2004).

Because of the heterogeneity of small enterprises this generalization may be a little doubtful. Nevertheless, the health and safety problems in SMEs are more a result of poor management of risk than of the actual magnitude of the hazards present (Walters, 2004).

In small enterprises the focus on safety is influenced by the particular culture of the owner of the enterprise. It is the owner who is the pivotal point of the enterprise and of the way health and safety is prioritized and implemented in daily work. The owner has to deal with many different issues and tasks every day, and will generally regard systematic work on safety and health as a more peripheral task (Hasle et al., 2004a,b).

In general, systematic work on health and safety in small enterprises is poor, as are other kinds of systematic management and planning. The employer/owner tends to entrust responsibility for safety to the employees themselves. Employers regard safety as an individual problem, as long as the necessary safety equipment is available (Axelsson, 2002; Hasle et al., 2004a,b).

\footnotetext{
* Corresponding author. Tel.: +45 45255149.

E-mail address: kirj@man.dtu.dk (K. Jørgensen).
}

It is important to realize that small enterprises seldom witness serious injuries, and that their ability to recognize risks and exposure to potential injury is limited. For this reason, their understanding and appreciation of the relevance of safety and health is also limited (Hasle et al., 2004a,b).

Over the last 5-10 years many different tools and methods have been developed and tested in small enterprises, but the general experience is that it is difficult to disseminate and create an interest in the results in small enterprises. Small enterprises need to recognize that these results give them something useful for their daily work, something which can make life simpler and which is easy to use. In the usual case the owner motivates by personal contact and when he has the opportunity of exchanging knowledge with colleagues (Hasle et al., 2004a,b). Another issue is that most accidents are apparently simple and related to human behavior, and very often result from everyday conditions which are not considered to be especially hazardous. This is perhaps another important reason why the rate of injury is high. All these points must be taken into account when developing a risk evaluation system for small enterprises.

Fig. 1 shows accident types for carpenters and is based on data imported from the Danish Working Environment Authority concerning notified accidents at work collected in the Danish register in the period 1993-2002. The Danish data was analyzed using the Dutch framework based on the 64 bow-ties (see below), and shows that the accidents relate to working on ladders, scaffoldings, constructions, manual handling, use of hand tools and transport.

The problem is that a layman cannot assess or prioritize the risks and risk factors involved simply by looking at a ladder, a 


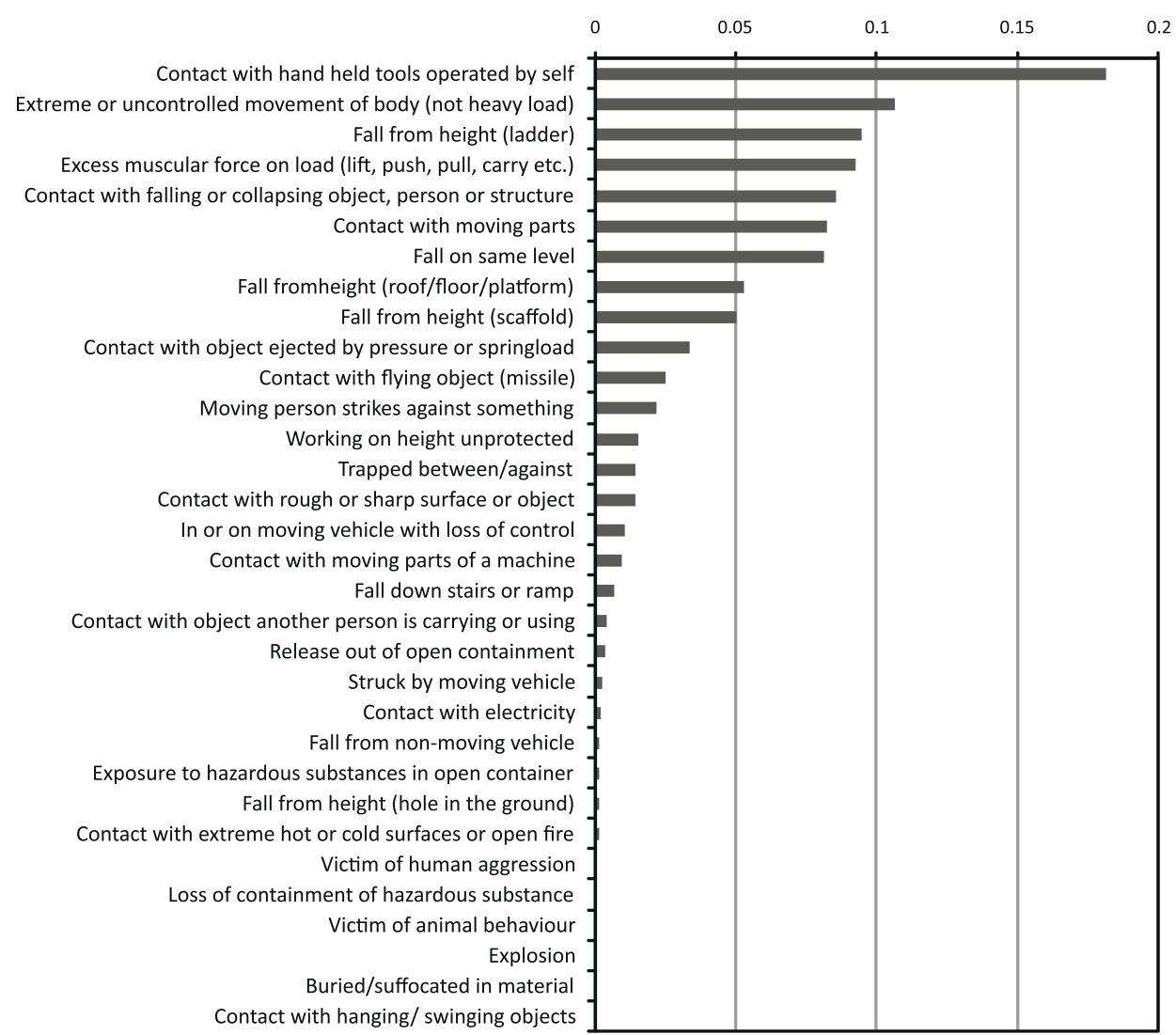

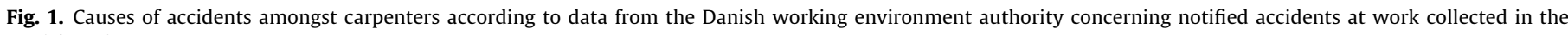
Danish register 1993-2002.

stairway or a vehicle. Evaluations of these trivial risks seldom occur in traditional risk assessments, even though the majority of injuries are due to such risks.

The WORM project has delivered a fully quantified occupational risk model (ORM), based on analysis of the causes and underlying causes of 9142 reported accidents in The Netherlands that took place over the course of 6 years (1998-2004) and which were investigated by the inspectors at the Dutch labour inspectorate (DLI). The accidents were analyzed by means of the Bow-tie model - a tool for integrating broad classes of cause-consequence models (Ale, 2006). The bow-ties describe the relationships between exposure to certain risks, factors that influence those risks, and the risk outcome in terms of probability of death, permanent injury and of recoverable injury (Ale, 2006).

A total of 36 generic hazards or bow-ties were identified and described in this systematic way. Some of these 36 bow-ties were divided into a few more detailed categories, so that the total number of hazards distinguished in the final system rose to 64. For each of these 64 hazards a number of safety barriers which can prevent an accident from occurring were identified. The ORM is also based on surveys containing a valuable set of data on exposure to hazards throughout the entire workforce in the Netherlands and giving the average exposure to hazards and conditions of safety barriers in The Netherlands, a statistic which WORM refers to as the Dutch national average (DNA) exposure and risk.

ORM is transferred into a software tool which allows users to make a quantified analysis of their specific risk and which can generate tailored advice on strategies for reducing risk for their organizations (WORM Metamorphosis Consortium, 2008). For each of the 64 bowties, the WORM project has identified the barriers that must be in place to prevent accidents from occurring, e.g. proper tools, maintenance, protection equipment, etc. To receive a tailored result, the user has to provide input (i.e. to answer questions) about each of his or her tasks, task durations, the activities that constitute those tasks, and the conditions under which these activities take place. This easily adds up to at least 50 questions. The input requirements are shown schematically in Fig. 2. If no data is provided for block 2 in Fig. 2, the conditions according to DNA are assumed in the software.

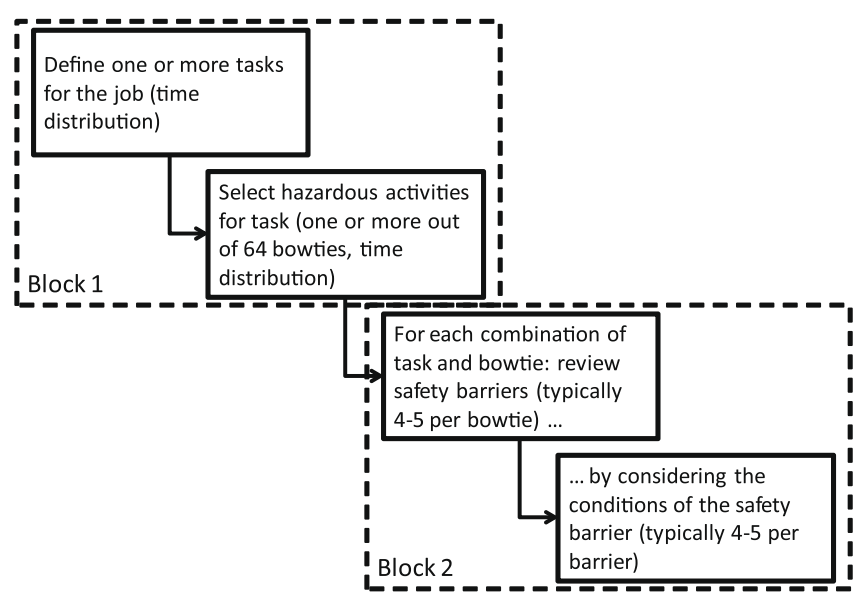

Fig. 2. Input to the WORM software. Block 1 deals with specifying time spent on hazardous activities. Block 2 deals with specifying factors that determine the level of risk. 


\section{The DanWORM project}

The unique results of the Dutch WORM project inspired us to make the results available for other countries and to collect further experience in the use of the method. A Danish team therefore decided to establish the DanWORM project. One aim of DanWORM is to make the Dutch software available to ordinary Danish users. This requires translating both the data and interface into Danish and adjusting the data to Danish conditions wherever necessary.

Within DanWORM it was however soon realized that the original WORM required such detailed and comprehensive inputs that widespread use of the software, especially by small enterprises, could not be expected.

The aims of DanWORM were therefore extended to include helping the end-user by:

A. Developing a "light" ORM version that can be used in SMEs.

$B$. Collecting the information required by ORM in an easy and well-documented way.

C. Developing recommendations for risk management procedures for SMEs.

In DanWORM's application, the target group consists solely of the SME employer or the employee him/herself, which means that the input requirements have to be drastically simplified. The approach adopted is to define standard hazard exposure profiles for a particular occupation. For each occupation a limited number of tasks typical for that occupation are defined. These "tasks" are expressed in terms that are familiar to the employer and employee. For each of these tasks the exposures to the various hazards are presented in the form of a hazard profile. The end-user has only to provide the time spent on his regular tasks. Applying the hazard profiles for these tasks will then automatically generate the user's hazard exposure. This simplifies the input requirements designated as block 1 in Fig. 2. Furthermore, an investigation is made of how to simplify the inputs designated as block 2, e.g. by avoiding duplications of questions that affect more than one barrier.

The system will be developed for two particular occupations for which empirical data has been collected, namely carpenters and caretakers, occupations which represent a large group of small enterprises which traditionally have a high level of accidents.

\subsection{Developing an ORM light version}

We realized that we should have to do the hard work for the small enterprises. This is to collect all the information needed in the ORM system and, if possible, answer most of the questions for the SMEs beforehand.

Small enterprises, even when in the same branch, will of course represent different risks owing to their different tasks, culture, consciousness, competence, etc. Our observations will result in an identification of the main differences of relevance to the generic risk level. The aim is that the small enterprises in the sector should be able to obtain information on the general risk level by answering questions which relate solely to the main differences. By observing tasks that are typical for certain occupations in certain business sectors, we aim to limit the questions to those that are relevant to these occupations, focusing on differences between enterprises within the same business sector.

We chose to follow a number of persons in three occupations and register their activities and related barriers continuously during a few full working days.

For each of the occupations we decided to follow 20 persons in 5-7 different small enterprises each for about $3 \mathrm{~d}$. We thus have observations for a total of 60 working days for each occupation.
We also interviewed each person about how often he/she carried out various tasks per month and per year, and the same question was put to the employer about all the employees.

This information taken together with our direct observation would give us a rather good idea of the activities carried out in these occupations and of the safety-barrier conditions. The data collected covers the data requirements of the Dutch ORM (Fig. 2). By inserting this information into ORM we will obtain knowledge of the real risk in small enterprises for each of the occupations observed.

This should provide a basis for the creation of a simple ORM light version targeted at small enterprises for specific occupations.

\subsection{The data collection of the information required for ORM}

Collection of the empirical data consists in recording the times that subjects are exposed to certain hazards while performing a particular task. To facilitate the data collection we developed a software application that runs on a handheld or palmtop computer (PDA). The small screen, the large amount of information to be collected, and the conditions obtaining during the observations necessitated very careful design of the interface and careful selection of relevant questions to be answered. The PDA tool is used to collect the following information on the subject under observation, in accordance with the data requirements of ORM (Fig. 2):

- The frequency and duration of a job-specific task.

- The frequency and duration of a hazardous activity within a particular task.

- The state of evaluation criteria for the safety barriers as defined by ORM each time a hazardous activity is observed. In the terminology of ORM, these evaluation criteria are denoted as "Probability Influencing Entities (PIEs)” (Ale, 2006). Registration of PIEstates in the PDA is binary, i.e. the status is either "correct" or "faulty".

Afterwards, we can combine and average the results for a single enterprise, or a group of enterprises, or the type of job. This provides a distribution of the PIEs, i.e. the number of observations in which a PIE is in a "correct" or "faulty" state.

Most occupations can be divided into a number of tasks and we decided that this should not exceed $7-8$, as this is the maximum number a pop-up on the PDA can show. Table 1 shows examples of tasks for carpenters and for caretakers. These tasks correspond to the data to be entered in the top-left box in Fig. 2.

A task consists of a number of consecutive and/or simultaneous activities - a hazard is linked to activities according to the 64 specific bowties. We call these the "hazardous activities", even if the activities are not hazardous in a traditional sense; the term denotes all general activities and situations, which may be everyday situations (e.g. walking), but where according to the accident registrations accidents like simple slips and lapses have occurred. The

Table 1

Tasks for carpenters and caretakers.

\begin{tabular}{ll}
\hline Carpenter tasks & Caretakers tasks \\
\hline $\begin{array}{l}\text { Construction of building frame, facades, } \\
\text { roofs, windows }\end{array}$ & $\begin{array}{l}\text { Gardening/outdoor area } \\
\text { maintenance }\end{array}$ \\
$\begin{array}{l}\text { Renoor construction and fittings } \\
\text { Renovation, outdoor }\end{array}$ & $\begin{array}{l}\text { Building maintenance } \\
\text { Operation of heating system } \\
\text { Ventilation and indoor climate }\end{array}$ \\
Demolition & system \\
Workshop work & Handling of waste \\
Administration, customer contact & Administration \\
Transport, purchase, waste removal & General technical tasks \\
& Servicing and contacts with the \\
& residents \\
\hline
\end{tabular}


Table 2

"Zero" level of classification of activities to be registered.

A. The activities/hazards related to the surface one walks/works on where there is a risk of falling

B. The activities/hazards concerning one's surroundings where there is a risk of being hit or hitting against something, being hit by collapsing or falling objects, flying objects or similar

C. The activities/hazards concerning what one is working with, where there is a risk of being cut (sharp edges), jammed, crushed, injured by moving tools or chemicals, etc.

D. The activities/hazards concerning very specific and infrequent high risks like fire, explosion, drowning, poisoning, etc.

transformation from bowtie to hazardous activities is exemplified in the following: One bowtie is made for "fall from height - placement ladder"; the transformation to hazardous activities is defined as "working on a placement ladder/risk of fall from height". The specification of hazardous activities/bowties for a task corresponds to the second box in Fig. 2.

Needing to make the registration simple, we discovered that it is possible to classify the 64 hazardous activities in three levels. The "zero" level consists of four groups as a main entry to all kind of hazardous activities. Table 2 shows this essential entry to hazardous activities:

Each of these main classifications has 2-5 subgroups, which in turn have 2-8 specific "hazardous activities" closely related to the specific 64 bowties in the ORM system (WORM Metamorphosis Consortium, 2008). Table 3 shows the full classification system of the 64 hazardous activities.

The three levels in the hazardous activities are used in the PDA configuration. These levels lead the observer to the right observation in such a way that at each level the observer can see all the choices on the PDA with no more than eight positions at a time, as illustrated in Fig. 3.

When a hazardous activity is registered on the PDA, the observer has to evaluate the presence of the barriers and their quality by means of criteria that correspond to the notion of probability influencing entities (PIE) in ORM. Table 4 shows an example of the barriers to "fall from height - placement ladder" as an illustration of the breadth of observations needed. Barriers in the framework of ORM are divided into primary safety barriers (PSB) and secondary support barriers (SSB) (Ale, 2006). The difference is principally theoretical, and for observation purposes it is the Secondary Support Barriers that are of interest.

This part is also difficult to overview and to handle during the observations because of the large number of barriers; however, the observer is led through the decisions that have to be made by the same kind of step-by-step procedure as used for the hazardous activities. Fig. 4 shows an example of the screen on the PDA, for the evaluation of the barriers.

\subsection{Developing recommendations for small enterprises}

We do not expect to find systematic risk management systems in small enterprises, because, as the literature shows, this is of little relevance to them. However, even though systematic risk management may not be practiced in small enterprises, they are compelled to cover many aspects of risk management in a more informal way.

Such is the situation of small enterprises and our goal should be to develop practices and competencies together with simple tools that can help them to control their risk situation under the prevailing conditions.

The following data is collected in support of this part of the project:
- Data about the lack of barriers as described under A and B.

- Interviews of the employer about his views on health and safety work and his manner of managing health and safety for his employees.

- General observations of how the work is carried out and dialogue with the employees during the observations.

The small enterprises that we invited to participate in the project were promised a workplace assessment in return for their participation. This is attractive for the following reasons:

- All enterprises are legally obliged to compile such a workplace assessment.

- Many small enterprises have never done this and have very little knowledge of how to do so.

- They receive a free professional workplace assessment based on the real risks.

The intention is to deliver the workplace assessment to the enterprise shortly after the data collection. In this connection we organize a meeting with both the employer and the employees where we discuss their views on their risk situation and the results of the workplace assessment. In addition, we encourage them to discuss "what to do about it and how" and so improve the health and safety conditions in the enterprise.

At the same meeting we tried to obtain feedback from the enterprise about their needs and the kind of tools, equipment, knowledge, or help functions they would consider useful for their work and acceptable to themselves. The simple philosophy behind this is: "If you would like to know what a specific group needs, why not ask them?".

\section{Preliminary results}

The preliminary results of the project concern the use of the PDA-application, data collection, the results of observations at a few small enterprises, as well as the findings of these observations.

It transpired that the PDA-application was very easy for a trained person to use. The three steps of the hazardous activities observation work very well. The first step, where one distinguishes between the four groups, seems to be especially useful in evaluating the risk (see Table 2).

It was easy to record the observations even when the activities and barriers changed quickly over shorter or longer periods. The next step will be to let new untrained persons use the tool and then to receive their feedback.

We note that, though it is not difficult to use the tool or to make the observations, it is difficult really to understand what to look for and to gain an overview of the many details. We therefore conclude that the observations still require a certain understanding of health and safety issues. The observations must cover the whole working day and also include those activities which, though not normally considered especially hazardous, are nonetheless included in the 64 "hazardous" activities, such as walking on same level.

We must also realize that it is time-consuming to follow people around for several working days. One could of course find data on the exposure by simply asking people what they do and how, as was done in the Dutch survey, but in our experience the subjects do not really know themselves. They do not think about it and they find they do many different things which change all the time. Even when we ask them how much time they spend on the main tasks in a year, their answers can be very vague.

The observations so far have provided good insight into the time distribution of tasks and the particular hazardous activities 
Table 3

Full classification of the hazardous activities as a basis for structuring the observation and registration of these activities during the field study.

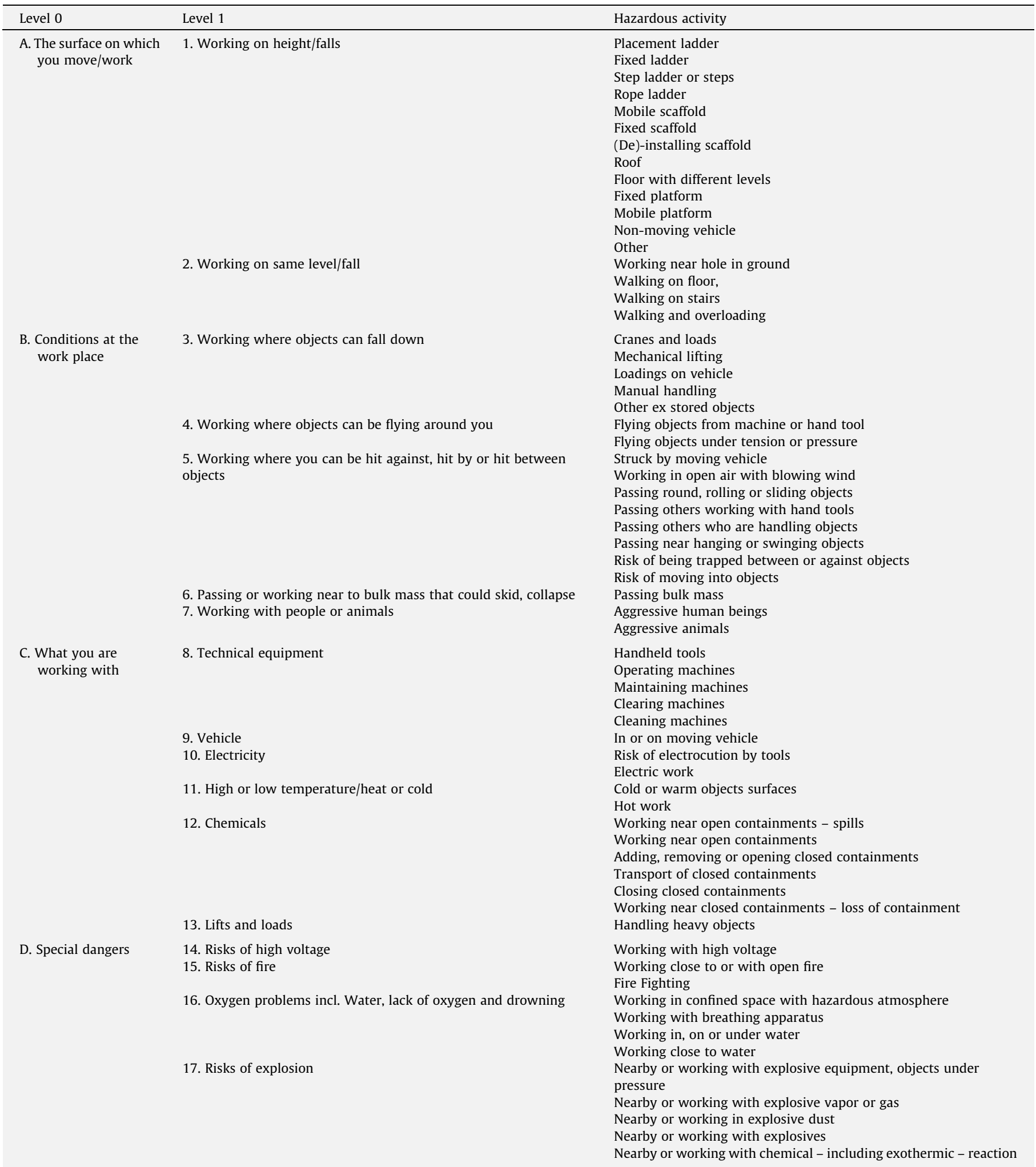

included. By means of this distribution, a preliminary "risk profile" could be calculated using the ORM software and this is presented in Fig. 5 for carpenters. It is interesting to compare this with the results of Fig. 1. Registration of PIEs did not lead to a definite conclusion that the condition of barriers was significantly different from the Dutch national average, and therefore the DNA was used in Fig. 5. Operational use by end-users of the observed activity profiles for tasks still requires further development of the ORM software. For the time being a pre-processor has been made that transforms input at task level into input files for the Dutch ORM 


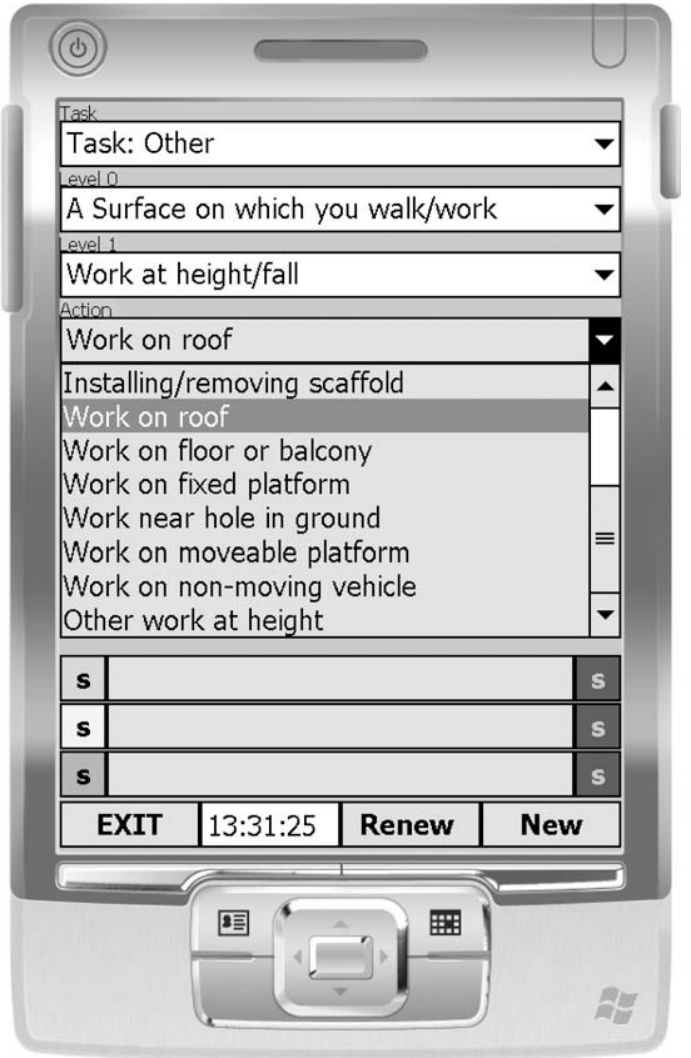

Fig. 3. Example of the PDA interface when selecting an activity to be recorded. The selected activity "working on roof" belongs to group A (surface on which you walk/ work), subgroup 1 (working at height/fall). Within this subgroup there are eight possible actions, cf. Table 3.

software. Yet it does not seem likely that the software will be actively used by the target group of SMEs.

Apart from the quantitative analysis using the ORM software, the observations using the framework of DanWORM (as described in Tables 2 and 3 ) lead to useful insights that can be imparted directly to the target group of SMEs, viz. in an approach towards work-place assessments.

The occupations were chosen because of their generally high rates of injury. We found that these jobs are characterized by work situations and work conditions that change from day to day and so are unpredictable.

The attitude towards health and safety in the enterprises involved in this project is very similar to that described in other research (Hasle et al., 2004a,b; Hasle et al., 2009; Vickers et al., 2003; Eakin and MacEachen, 1998; Walters and Lamn, 2003).
The employees cannot perceive the risks they are exposed to; finishing the job is their first priority; the employer expects them to look after themselves. On the other hand, the enterprises that actually agreed to participate showed an interest and wanted to learn how to prevent injury. They asked questions about health and safety issues and were willing to follow good advice.

The results of the observations and the interviews can be illustrated by the workplace assessment of the carpenter enterprise. Because the work varies a great deal, it makes sense to divide the workplace assessment into two parts: a general part that covers general risks and preventive actions, which require the employer to take initiatives to remedy the situation; and a second part that covers the risks that the employee has to be aware of before he begins a new job.

It is out of the question that the employer of such a small enterprise should be able to make a full risk assessment of all the new jobs his employees have to do. He can of course make demands and give instructions as well as provide the tools and equipment that the employees need to work safely, and he can inspect while he controls the work that has to be done.

The first general risk assessment for one small carpenter enterprise contains a proposal for a health and safety plan. These firsthand recommendations for the SMEs are based on the direct observations and the dialogue with the employers and employees. It was found that the problems that should be addressed by the employer also require specific recommendations to the employees and that both parties must make an effort to ensure safety at work. The recommendations apply to:

1. Cleaning of tools, machines, vehicles and workplaces.

2. Hoisting of materials.

3. Placement of electrical wire.

4. Placement of handheld tools when not used, in storage or under transport.

5. Maintenance of tools and machines.

6. Safety equipment for limiting exposure to dust.

7. Safety guarding on machines.

8. Working with windows or glass materials.

9. The availability of personal safety equipment.

10. The use of mobile telephones during transport.

The second risk assessment targeted at the employees contains a one-page and 10-point risk-awareness program to be checked off. This takes just a couple of minutes of the employee's time before he/she begins a new job. The 10-points are the following:

1. Safety at scaffoldings: check the railing, the floor, the cleaning, the distance between the scaffolding and the house, the manhole and evaluate the risk of falling in relation to your own well-being.

Table 4

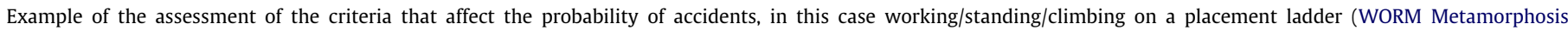
Consortium, 2008).

\begin{tabular}{|c|c|c|c|}
\hline Activity hazardous & Primary safety barriers & Support safety barriers & Evaluation criteria (probability influencing entity (PIE)) \\
\hline \multirow{12}{*}{$\begin{array}{l}\text { Work at placement ladders/Risk } \\
\text { of falling }\end{array}$} & 1. The ladder strength & 1. The type of ladder and the strength & Conditions of ladder steps \\
\hline & & & Inspection of ladder capacity and length \\
\hline & & & Maintenance and storage \\
\hline & & & Cleaning \\
\hline & 2. The ladder stability & 2. The placement and protection of the ladder & Placement on the ground \\
\hline & & & Placement at the top, angle \\
\hline & & & Protection against traffic \\
\hline & 3. The user stability & 3. The ability of user to stay on the ladder & Position on the ladder \\
\hline & & & Personal condition \\
\hline & & & Use of both hands to hold onto the ladder \\
\hline & & & External forces influence \\
\hline & & & Appropriate movements \\
\hline
\end{tabular}




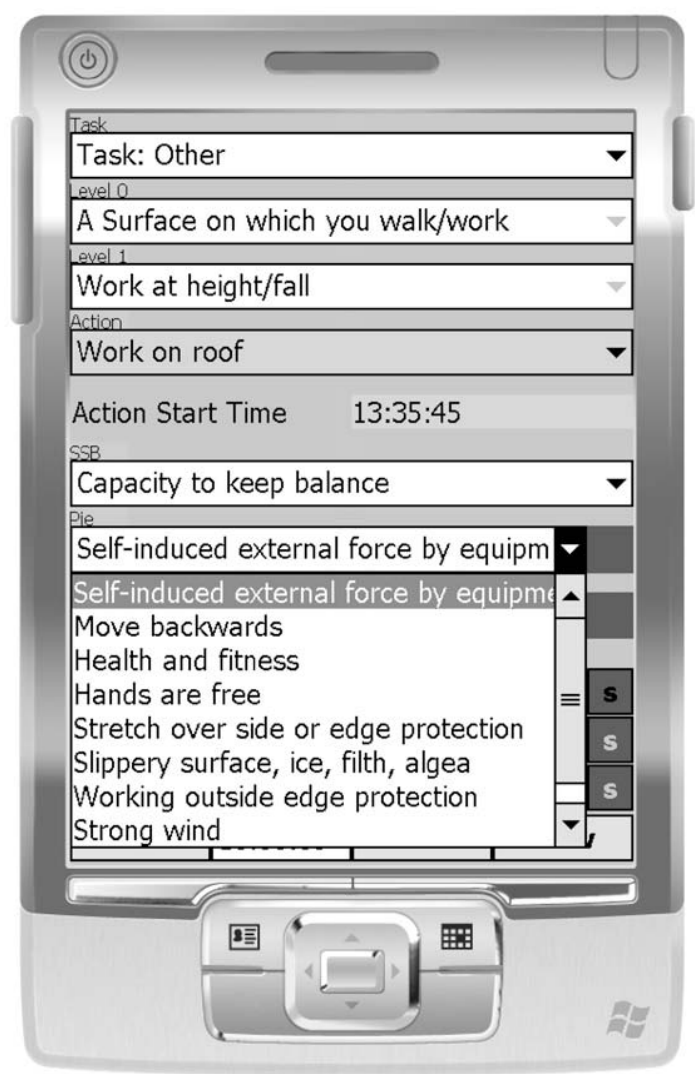

Fig. 4. Example of the PDA interface when selecting the status of the probability influencing entities (PIEs) that affect the quality of the secondary support barrier (SBB): "Capacity to keep balance" for the activity "working on roof" (cf. Fig 2). There are eight PIEs for this barrier. Each of the PIE's can be assigned the status "correct" or "faulty" for each recording of an activity.

2. Safety at ladders: check the maintenance, the stability, the strength, the length, the firmness of the ladder's footing and evaluate the risk of falling in relation to your own well-being.

3. Safety when working on a roof or at heights: check the railings, the floor, fall resistance, the surface strength and evaluate the risk of falling in relation to your own well-being.
4. Safety at tools and machines: check the safety guards, maintenance, the placement of materials, and the placement of electrical wire.

5. Personal safety protection: evaluate the needs and the availabilities.

6. Safety in manual handling: check for heavy lifting, the need for hoisting equipment, the right lifting technique, the use of equipment such as a platform or small stepladder to ensure a good working position.

7. Safety wherever you are walking: check the cleaning, the maintenance of the main road, the placement of materials, waste, wires, tools, etc.

8. Safety in handling waste and waste removal: check the need for personal safety equipment.

9. Safety in transport both at the site and in the traffic: check the traffic behavior, the maintenance and cleaning of the vehicle.

10. Be conscious of acute risks in the working situation such as:

- Sharp equipment, risks of being crushed or jammed, risks of being hit against or being hit by something, fire risks, chemicals risks, dust risks, explosion risks, risks of materials collapse or fall, risks of slipping or irregular surfaces, risks of falls in general, risks from other road users.

This list may seem long, but with some training and everyday use, the risk evaluation done by the employee in the concrete work situation becomes practicable and will not take much of the professional carpenter's time. Most professional carpenters would properly say that they do this all the time and in this case the list reminds them to be systematic in their evaluation. For the young carpenter with less experience the list can serve as a checklist.

The need for a risk assessment for the enterprise and the employer (as required by legislation) as well as the employee's own daily risk assessment has been very clear in our observations. The employees need to be trained to handle their daily risk situation in a professional way.

This does not mean divesting the employer of responsibility, but rather supporting the collaboration between the latter and his employees, and qualifying the dialogue about working conditions. One can never eliminate all risk of accident, but one can learn to handle the risk situations in a way that prevents the risks from leading to accidents.

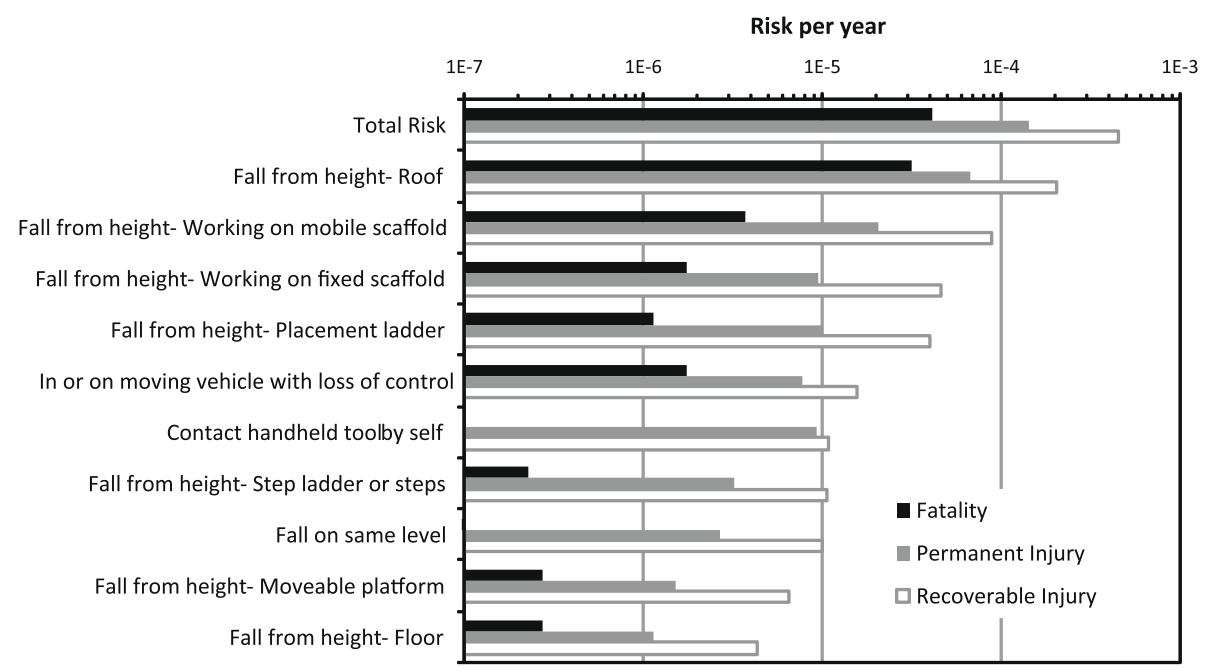

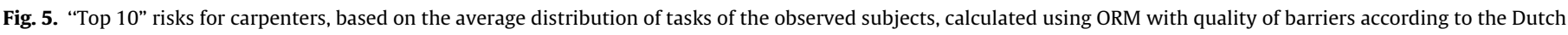
national average. 


\section{Discussion}

The system of collecting information on the activities and hazards associated with a certain occupation, as developed in this project, has been shown to be very easy and useful. With a PDA and the interface one can, with very little effort, collect very detailed information about activities, hazards and safety barriers for a working day.

Nevertheless, one has to understand the system and be able to evaluate safety barriers in relation to the hazards and activities, and that requires some experience. Knowing that small enterprises have neither the time, the knowledge nor the necessary awareness of the risks, we must conclude that small enterprises would never use this data collection system themselves.

For professionals however the system can be a way of collecting data to produce the same kind of generic version of occupations or branches, or even of concrete enterprises - as has been done in this project. Larger enterprises could also use the system to register the tasks and activities actually done by the employees in their working day. What a generic version of a risk profile will look like for a certain occupation is still part of our project, but the outline is starting to take form.

One of our concerns is that, even when we follow people for several days, we may not discover the kind of risks that occur only once or twice a year. So the method has its limits. Nevertheless, the system produces a fine overview of the general risks and in particular includes the large group of risks that is rarely included in traditional risks assessments, i.e. those one may call "trivial risks", like falls on the floor or stairs, sprain and strains after a wrong or heavy lift, sharp tools or materials and so forth.

We found that the division of the risk focus into four parts was extremely useful (see Table 2 ).

A. Look for the risk of falling from where you are walking and where you have your feet.

B. Look for the risks from your surroundings, the risk for being hit by or hit against something, being hit by collapsing or falling objects, flying objects or similar.

C. Look for the risks from what you are working with and use your hands for. Risks such as sharp surfaces, sticking, squeezing situations, moving tools, chemicals, etc.

D. Look for the special and very specific risks related to fire, explosion, drowning, poisoning, etc.
Generally speaking, most risk assessments look only at group D, because of the potentially severe consequences if or when these risks are realized. Fortunately, in most enterprises these risks very seldom occur. Where these risks exist, they must receive much attention, but most enterprises do not have these potentially severe risks. They "only" have the banal risks which no-one thinks worth dealing with, perhaps because the tasks in many enterprises do change all the time with new surroundings, new customers, new products, new weather, new colleagues, new tools, etc.

Maybe we need to make a distinction between the kind of risk assessment the employer has to make and the kind of risks the employees have to be aware of. If we make this distinction, there remains the large task of training the employees to be aware of and deal with the risks they meet on a daily basis during the ever-changing occupational conditions.

This comes close to the basic concept of safety culture. We see that the Dutch ORM and The DanWORM results can be fine supplements to this process.

\section{References}

Ale, B.J.M., 2006. The Occupational Risk Model - Final Report of the Workgroup on ORM. TUDelft, The Netherlands.

Axelsson, C., 2002. Formalisering som hinder \& mölighet I småföretag En studie av arbetsmiljöarbete ur eet lärandeperspektiv. Luleå Tekniska Universitet, Sweden.

Eakin, J.M., MacEachen, E., 1998. Health and the social relations of work: a study of the health-related experience of employees in small workplaces. Sociology of Health \& Illness 20 (6), 896-914.

European Agency for Safety and Health at Work, 2003. Improving Occupational Safety and Health in SMÉs. EU-publication office, Spain.

Hasle, P., Limborg, H.J., Ledskov, A., Nalholm, E., 2004a. Arbejdsmiljøarbejdet i Mindre og Mellemstore Virksomheder - en Litteraturanalyse. IPL, DTU, Danmark (in Danish).

Hasle, P. et al., 2004b. Arbejdsmiljøarbejdet I Mindre og Mellemstore Virksomheder - en Litteraturanalyse. DTU, Denmark.

Hasle, P., Kines, P., Andersen, L.P., 2009. Small enterprise ownerś accident causation attribution and prevention. Safety Science 47, 9-19.

Vickers, I., Baldock, R., Smallbone, D., James, P., Ekanem, I. 2003. Cultural Influences on Health and Safety Attitudes and Behaviour in Small Businesses. Research report 150 , HSE BOOKS, UK.

Walters, D., Lamn, F., 2003. OHS in Small Organisations: Some Challenges and Ways Forward. Working Paper 15, National Research Centre for Occupational Health and Safety Regulation \& National Occupational Health and Safety Commission, Gold Coast, The Australian National University.

Walters, D., 2004. Representation in health and safety in small enterprises in Europe. Industrial Relations Journal, 35(2).

WORM Metamorphosis Consortium, 2008. The Quantification of Occupational Risk - the Development of a Risk Assessment Model and Software. RIVM, Report 620801001/2008, Bilthoven, The Netherlands. 